\title{
Perancangan 22 Kartu Arkana Mayor Tarot Astadewa untuk Aplikasi Mobile
}

\author{
Elsa Serina Putri dan R. Eka Rizkiantono \\ Departemen Desain Produk Industri, Fakultas Teknik Sipil dan Perencanaan, Institut Teknologi \\ Sepuluh Nopember (ITS) \\ e-mail: elsaserina@gmail.com, ekaindian007@gmail.com
}

\begin{abstract}
Abstrak-Perkembangan industri smartphone semakin naik setiap tahunnya, berikut industri program aplikasi. Salah satu dari lima program aplikasi yang paling banyak diunduh oleh masyarakat adalah program aplikasi dalam kategori gaya hidup, salah satu gaya hidup yang mengikuti perkembangan smartphone adalah gaya hidup tarot. Gaya hidup tarot adalah gaya hidup yang bekembang di Indonesia semenjak terbitnya buku Bunga Rampai Wacana Tarot karya Ani Sekarningsih. Fenomena perkembangan gaya hidup ini memiliki potensi untuk dibuatnya media baru yang mendukung perkembangan smartphone, yaitu aplikasi mobile. Tarot sendiri adalah satu set kartu berisi 22 kartu arkana mayor dan 56 arkana minor yang digunakan sebagai sebuah media meramal. Tarot sangat mudah dirasuki oleh budaya dan kisah yang berbeda-beda, selama masih berkesinambungan dengan makna universal. Dalam perancangan ini, budaya yang digunakan adalah wayang purwa mengangkat kisah Mahabharata. Perancangan kartu tarot dan aplikasi mobile menggunakan metode riset kualitatif berupa observasi, studi literatur, FGD, dan wawancara mendalam dengan penganut gaya hidup tarot, developer aplikasi, dan juga pakar wayang.

Hasil yang diharapkan dari perancangan ini, dengan adanya sebuah aplikasi mobile dengan konten tarot lokal, maka dapat menginspirasi para desainer untuk membuat tarot dengan konten lokal, sehingga dapat mendukung perkembangan industri tarot Indonesia.
\end{abstract}

Kata Kunci-Aplikasi Mobile, Astadewa, Mahabharata, Tarot.

\section{PENDAHULUAN}

$\mathrm{P}$ ERKEMBANGAN smartphone di Indonesia semakin melonjak setiap tahunnya. Sebuah laporan dari badan penelitian market online, eMarketer, menyatakan bahwa akan terdapat dua miliar pengguna smartphone aktif di seluruh dunia pada tahun 2016, dan Indonesia adalah salah satu negara yang mengalami pertumbuhan terbesar setelah Cina dan India. Ditunjang oleh angka demografi penduduk yang besar, diperkirakan Indonesia akan melampaui 100 juta pengguna aktif pada tahun 2018, yang menjadikan Indonesia negara dengan populasi pengguna smartphone terbanyak keempat di dunia (setelah Cina, India, dan Amerika Serikat) [1].

Smartphone dilengkapi dengan teknologi hardware dan software yang mumpuni untuk melakukan hal-hal yang sebelumnya hanya bisa dilakukan di perangkat desktop. Pekerjaan yang dulu hanya bisa dilakukan di satu tempat, kini dapat dilakukan di mana dan kapan saja, tidak terikat ruang dan waktu. Kultur dinamis dan praktis yang ditawarkan oleh smartphone diprediksi akan menguasai perkembangan industri dunia informasi dan teknologi komunikasi.

Dalam prakteknya, software berupa program aplikasi adalah salah satu ujung tombak keberhasilan smartphone. Program aplikasi berperan sebagai pembuka jalan bagi pemanfaatan maksimal dari kultur dinamis dan praktis yang ditawarkan oleh smartphone. Program aplikasi mobile kini menjadi bidang dengan potensi yang sangat besar dalam industri perkembangan informasi dan teknologi komunikasi.

Riset Com Score (2012) menyatakan pengguna perangkat smartphone lebih banyak menggunakan program aplikasi $(51,1 \%)$ daripada web browsing $(49,8 \%)$ dari perangkat smartphone mereka. Dari riset Gartner (2014) didapatkan bahwa pada tahun 2017, kegiatan mengunduh aplikasi mobile akan mencapai angka 268 milyar dengan estimasi penghasilan 77 milyar Dollar Amerika. Berdasarkan laporan analisis bisnis, industri pengembangan aplikasi telah menyumbangkan revenue 10 milyar Euro dan membuka 529.000 lapangan pekerjaan di 28 negara Uni Eropa [2].

Berdasarkan riset bertema Indonesia Mobile Data yang dikeluarkan oleh MoboMarket didapatkan bahwa program dari 29 kategori aplikasi, lima aplikasi mobile yang paling banyak diunduh oleh pengguna smartphone Indonesia adalah, permainan $(43,71 \%)$, sosial $(12,9 \%)$, fotografi $(8,84 \%)$, dan gaya hidup $(7,30 \%)$. Pada perancangan ini akan dikhususkan pada program aplikasi dalam kategori gaya hidup [3].

Gaya hidup tarot adalah sebuah gaya hidup yang saat ini tengah mengalami kepopuleran. Walaupun Tarot telah hadir sejak abad ke 15, namun kepopulerannya baru dapat dilihat dengan jelas belakangan ini. Di Indonesia sendiri, kepopuleran Tarot dalam skala nasional baru dimulai setelah terbitnya buku Bunga Rampai Wacana Tarot karya Ani Sekarningsih CTGM (Certified Tarot Grand Master) pada April 2001, yang kemudian disusul oleh terbitnya Tarot Wayang dan Panduan Tarot Wayang pada tahun 2002. Kedua karya ini memprakarsai berbagai Komunitas Tarot di Indonesia, salah satunya Komunitas Full Moon Surabaya (2009), Komunitas Tarot Jakarta (2011), Komunitas Dewaroetji Yogyakarta (2012), dan Indonesian Tarot Association (ITA) (2014). Kedua karya ini juga telah memicu berbagai penulis dan penerbit Indonesia untuk berlomba-lomba menerbitkan Tarot dan buku panduan tarot. Adapun ciri khas dari penganut gaya hidup tarot adalah; dapat membaca tarot (baik dalam tahap beginner atau profesional), memiliki ketergantungan kepada Tarot (Seorang pembaca tarot akan berkomunikasi dan 
menggunakan tarot paling minim sekali sehari), ketertarikan untuk mempelajari visual dan simbolisme dari kartu tarot, gemar mengoleksi dek tarot, senang mempelajari perbedaan antara satu tarot dengan tarot yang lain. Namun, untuk mempelajari keseluruhan 78 kartu dalam satu dek dan bagaimana cara menggunakannya tanpa mengalami kecondongan arti diperlukan ketekunan dan dedikasi, dan di situlah peranan smartphone dapat menjadi signifikan. Selain digunakan sebagai sarana membaca tarot, kelebihan aplikasi tarot yang paling disukai oleh pengguna adalah ragam dek yang digunakan pada aplikasi mobile.

Dek yang paling standar digunakan, baik dalam aplikasi mobile maupun konvensional, adalah Tarot Rider-Waite-Smith yang dipublikasi pada tahun 1910, dek ini adalah dek yang paling populer dan sering digunakan sebagai panutan dalam pembuatan dek baru. Namun penggunaan dek lain juga tidak mengurangi fungsi dari aplikasi, malah menambah daya tarik dari aplikasi mobile itu sendiri. Pengembang aplikasi mobile tarot, The Fool's Dog, bahkan telah membuat aplikasi yang terdiri dari kurang lebih 60 dek tarot yang berbeda [4]. Keragaman dek ini adalah kelebihan utama dari aplikasi mobile, karena pengguna dapat menikmati beragam visual kartu tarot dan deskripsinya dalam satu media tanpa harus repot membawa beberapa dek tarot dan buku panduannya secara sekaligus.

Dalam wawancara yang sama, Eria Andi Nugroho mengatakan bahwa hal ini dikarenakan budaya Tarot masih dinilai baru di Indonesia, sehingga hanya sedikit orang yang benar-benar mengerti dan mempelajari makna Tarot.

Rasukan budaya dalam berbagai media populer terbukti telah meningkatkan minat masyarakat baik lokal maupun asing terhadap budaya tersebut.

Belajar dari pengetahuan tersebut, penulis ingin mencoba menuangkan unsur budaya Indonesia ke dalam Tarot sebagai upaya pelestarian budaya.

Terdapat dua kisah yang paling besar dalam pagelaran kesenian Wayang Purwa yaitu kisah Ramayana dan Mahabharata, sementara Ramayana berfokus kepada pemerintahan kerajaan dan pengejaran cinta, Mahabharata bersifat lebih universal dengan mengangkat topik sifat paling dasar manusia yaitu kebaikan melawan keburukan, sebab dan akibat, hitam dan putih, sehingga cerita Mahabharata lebih cocok untuk diadaptasi kedalam tarot yang bersifat universal.

Berdasarkan informasi tersebut, penulis menciptakan tarot Astadewa sebagai proyek mahasiswa yang akan mengadaptasi Wayang,kisah Mahabharata dalam pertunjukkan Wayang Purwa.

Berfungsi sebagai konten data dari aplikasi mobile, Tarot Astadewa diharapkan dapat membawa budaya Indonesia dengan kedalaman konten dan visual yang lebih lengkap dari dek tarot pendahulunya.

\section{A. Batasan Masalah}

1) Perancangan tidak mencakup penjualan atau pemasaran.

2) Kartu Tarot hanya mencakup 22 kartu arkana mayor.

3) Jumlah sebaran kartu tarot yang terdapat dalam aplikasi mobile Tarot Astadewa disesuaikan dengan waktu perancangan.
4) Cek uji analisis dan kelayakan kartu maupun aplikasi ditangani oleh Komunitas Tarot Full Moon Surabaya.

\section{A. Rumusan Masalah}

Masalah yang akan dipecahkan dalam penelitian ini adalah: "Bagaimana cara merancang visualisasi kartu tarot yang dapat menonjolkan keterampilan seni wayang untuk digunakan ke dalam aplikasi mobile?"

\section{B. Maksud dan Tujuan}

1) Memaparkan proses penciptaan desain tarot Astadewa dengan menggunakan simbolisasi dan makna yang ada di dalam kisah Mahabharata dalam wayang purwa.

2) Dengan adanya penciptaan tarot lokal yang baik, maka desain aplikasi tarot mobile dapat sebagai sebuah inovasi dan panutan yang dapat diaplikasikan pada media serupa yang menghas

\section{TINJAUAN PUSTAKA}

\section{A. Kajian Teori Objek Desain}

\section{1) Tarot}

Tarot adalah permainan kartu berjumlah 78 lembar yang menyebar di berbagai belahan Eropa pada abad ke 15. Kartu yang awalnya digunakan untuk permainan ini diperkirakan mulai beralih fungsi pada abad ke 18, hingga kini kartu tarot lebih sering digunakan sebagai media meramal. Kartu tarot terdiri dari 22 Arkana Mayor dan 56 Arkana Minor [5].

\section{2) Mahabrata dalam Wayang Purwa}

Wayang purwa adalah konten yang digunakan dalam media tarot. Kisah Mahabharata dalam wayang purwa berkiblat langsung kepada kisah asli Mahabharata yang berasal dari India, namun disusupi oleh beberapa karakter khas jawa seperti Punakawan dan juga terdapat perubahan cerita seperti kisah pernihakan Drupadi untuk disesuaikan dengan budaya Jawa [6].

3) Pembabakan Karakter Wayang Mahabharata ke Dalam

Tarot Mayor Arkana.

- The Fool - Sang Dungu - Dewi Durgandini

- The Magician - Sang Pamong - Semar

- The High Priestess - Sang Arif - Dewi Saraswati

- The Empress - Sang Ibu - Dewi Kunti

- The Emperor - Sang Penguasa - Duryudana

- The Hierophant - Sang Penuntun - Yamawidura

- The Lovers - Asmara - Kresna \& Rukmini

- The Chariot - Kereta - Kereta Kresna

- Strength-Kekuatan-Bima

- Hermit - Sang Petapa - Bengawan Abiyasa

- The Wheel of Fortune - Kehidupan - Gunungan

- Justice - Keadilan -- Yudhistira

- The Hanged Man - Kepasrahan - Resi Bisma

- Death-Kematian - Batara Yama

- Temperance - Kesetiaan - Drupadi

- The Devil - Tipu Daya - Sengkuni

- The Tower - Ketidakberdayaan - Durga

- The Star - Harapan - Srikandi

- The Moon - Kekecewaan - Dewi Gandari

- The Sun - Matahari - Batara Surya

- The Judgement - Pengadilan - Dewi Amba 
- The World - Kesempurnaan - Dewaruci

4) Aplikasi Mobile

Aplikasi mobile adalah sebuah program yang digunakan untuk perangkat seperti telepon genggam. Aplikasi Mobile memiliki ciri-ciri khas yaitu: Ukuran yang kecil, memori yang terbatas, daya proses terbatas, mengkonsumsi daya yang rendah [7].

\section{METODE PENELITIAN}

\section{A. Wawancara Mendalam}

Wawancara mendalam dilakukan dalam tiga tahap demi mengelompokkan informasi yang dibutuhkan.

1) Wawancara pertama mengenai keberadaan Tarot Indonesia. Wawancara ini dilakukan untuk mengetahui kebutuhan pasar penggemar tarot Indonesia, serta halangan dan peluang yang dimiliki oleh pasar tarot Indonesia

2) Wawancara yang kedua adalah mengenal lebih jauh mengenai aplikasi mobile tarot, untuk mengetahui fungsi dan ekspektasi apa yang ingin disampaikan oleh developer

3) Wawancara yang ketiga adalah dengan tour guide di Keraton Yogyakarta yang menjelaskan secara detail mengenai arti dan makna tersembunyi dari simbol-simbol yang digunakan dalam perwayangan, sekaligus untuk mengetahui sejarah mengapa Wayang selalu identik berlatar belakang Keraton.

\section{B. Focus Group Discussion (FGD)}

1) Fokus grup pertama dilakukan di awal perancangan sebagai sarana pengenalan sekaligus pengamatan pengguna, dalam perancangan ini pengamatan difokuskan pada anggota komunitas tarot Full Moon Surabaya. Pertanyaanpertanyaan yang diberikan pada segmen ini fokus pada tingkah laku dan kebiasaan pengguna yang berkaitan dengan tarot.

2) Fokus grup kedua dilakukan untuk mendalami konten serta elemen visual dari konten baik tarot maupun aplikasi mobile. Fokus grup ini bertujuan untuk melihat apakah tarot serta aplikasi mobile yang sudah beredar di pasaran telah memenuhi kebutuhan pengguna, fokus grup ini juga dapat disebut sebagai usability test.

\section{Observasi}

1) Observasi terhadap aplikasi sejenis yang memiliki target audiens dan tema serupa dilakukan untuk menganalisis cara berjalannya sebuah program, termasuk peletakan antarmuka dan bagaimana tingkat kenyamanan pengguna dalam mengoperasikannya. Aplikasi mobile yang diobservasi dan dianalisis adalah: Galaxy Tarot Pro, dan Tarot Sampler. Analisis dilakukan untuk memahami elemen-elemen apa saja yang terdapat dalam aplikasi di atas. Analisis ini dilakukan untuk mengetahui bagaimana aplikasi-aplikasi tersebut bekerja dengan baik sekaligus mampu menggabungkan visual aplikasi dengan visual tarot yang digunakan.

2) Observasi kedua dilakukan dengan mengunjungi Keraton Yogyakarta, museum Wayang Sriwedari dan Sanggar Wayang Orang Sriwedari. Observasi ini untuk melihat secara langsung bagaimana artefak, gaya gambar, kostum, relik, sekaligus mempelajari sejarah-sejarah mengenai wayang lebih dalam.

\section{Usability Test}

Usability Test, merupakan serangkaian tes yang melibatkan audiens, yang bertujuan untuk mengetahui apakah aplikasi yang dibuat telah bekerja dengan baik dan memenuhi kebutuhan audiens. Tes ini dilakukan dengan cara meminta audiens untuk menggunakan aplikasi eksisting dan mengamati bagaimana audiens mengoperasikan aplikasi tersebut sambil memberikan tes-tes kecil dalam mengoperasikan aplikasi dan memberikan pertanyaan diakhir sesi untuk mengetahui apakah aplikasi telah berjalan dengan baik, bagaimana tanggapan audiens berikut kelebihan dan kekurangannya. Tes digunakan untuk mengetahui apakah aplikasi telah bekerja sesuai dengan yang diinginkan oleh perancangan, dan bagaimana cara memperbaiki kekurangan dari aplikasi.

\section{E. Quality Check}

Ketika tarot dan aplikasi mobile telah mencapai tahap prototype, maka akan dilakukan tes yang serupa dengan usability test, tahap ini dilakukan untuk mengetahui apakah perancangan telah menjawab kebutuhan pengguna. Proses ini akan dilakukan di tahap akhir perancangan.

\section{F. Studi Literatur}

Studi literatur adalah teknik pengumpulan data dengan mencari literatur yang sesuai dengan penelitian yang dikaji, dalam penelitian ini, kata kunci topik yang dikaji adalah aplikasi mobile, tarot, wayang, dan Mahabharata. Studi literatur telah disajikan dalam Bab Tinjauan Pustaka, yang kemudian akan dikerucutkan dan dianalisis demi menjawab rumusan masalah.

\section{HASIL DAN PEMBAHASAN}

\section{A. Konsep Dasar}

Perancangan ini adalah perancangan yang mengkombinasikan elemen budaya modern melalui aplikasi mobile, dan elemen kultural melalui desain wayang, maka tema visual yang akan digunakan pada output perancangan adalah penggabungan tema cultural modern, dimana kedua unsur modern dan kultural disatukan sehingga membentuk sebuah kriteria desain yang baru.

\section{B. Konsep Visual Tarot}

Awalnya konsep visual tarot berbasis pada pengorangan wayang untuk membuat wayang menjadi lebih terlihat tiga dimensi, namun setelah mengalami FGD dan post test, konsep visual yang lebih disenangi oleh subjek penelitian adalah konsep yang mengadaptasi langsung desain wayang yang sudah ada kemudian di modifikasi gestur dan gerakannya untuk disesuaikan dengan kisah dan interpretasi dari kartu tarot.

\section{Kriteria Desain Aplikasi Mobile}

1) User Interface

- Model Navigasi

Berdasarkan observasi pada aplikasi sejenis berikut dengan 
literatur Empat Model Navigasi yang dijelaskan oleh Jeniffer Tidwell [7], ditarik kesimpulan bahwa model navigasi yang paling cocok untuk aplikasi mobile Tarot Astadewa adalah model navigasi $H u b$ \& Spoke

\section{- Alat Kendali}

Terdapat berbagai macam jenis gestur pada alat kendali berupa direct manipulation touch screen, namun aksi yang didukung oleh aplikasi adalah: single touch.

- Layout

Layout yang digunakan dalam konsep perancangan ini menggunakan gaya simetris yang memiliki tujuan untuk mengkotak-kotakan daya lihat pengguna sehingga pengguna dapat dengan mudah menemukan apa yang dicari.

2) Visual

- Tipografi

Berdasarkan observasi aplikasi sejenis, pada umumnya, jenis tipografi pada aplikasi tarot menggunakan jenis serif untuk menciptakan kesan antik. Sehingga diputuskan pada aplikasi mobile Tarot Astadewa akan mengacu pada tipografi serupa yang disesuaikan oleh tema, dan juga menggunakan jenis tipografi serif untuk badan kategori dan konten.

- Warna

Elemen warna pada aplikasi memberikan rupa fungsi selain fungsi dekorasi. Warna yang dipilih dalam aplikasi Tarot Astadewa dibuat kontras dengan kartu tarot Astadewa untuk mendukung kesan estetika.

\section{Sketsa dan Alternatif Desain Tarot}

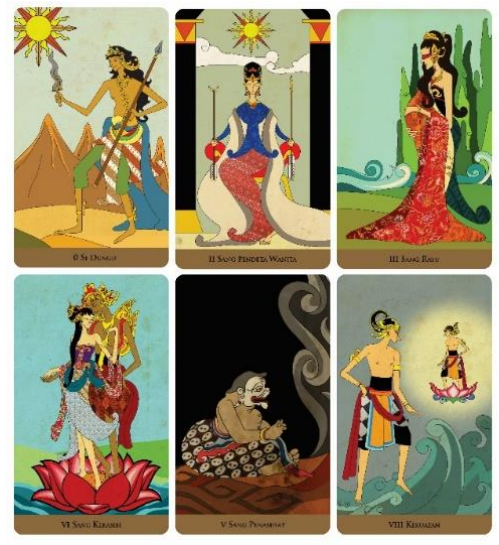

Gambar 1. Alternatif Pengorangan Wayang 1.

Tarot adalah sebuah media yang berukuran kecil, sehingga penyederhanaan gaya gambar dibutuhkan agar tidak terjadi design clutter. Awalnya tarot Astadewa menggunakan konsep wayang yang diorangkan untuk memberikan gaya gambar yang berbeda dengan eksisting wayang. Penggunaan media vektor dengan gaya gambar kartun dilakukan pada alternatif pertama untuk memberikan kesan simpel dan modern, sementara penggunaan ilustrasi berbentuk manusia dilakukan pada alternatif kedua dengan menggunakan media cat air. Namun terdapat perbedaan pendapat pada kedua alternatif ini karena kesan wayang yang didapat tidak terlalu terlihat. Kedua alternatif tersebut memberikan gaya gambar yang baru namun menyederhanakan kerumitan detail yang merupakan elemen estetika utama pada wayang, sehingga dibuatlah alternatif ketiga. Pada alternatif ketiga, visual wayang digunakan sebagaimana adanya, dan digambar dalam pose bergerak layaknya manusia disesuaikan dengan kisah, makna, dan interpretasi tarot. Karena menggunakan desain asli wayang yang kaya dan memiliki detail yang rumit, penyederhanaan dilakukan dalam bentuk penyederhanaan warna, sehingga kartu hanya menggunakan warna hitam dan putih.

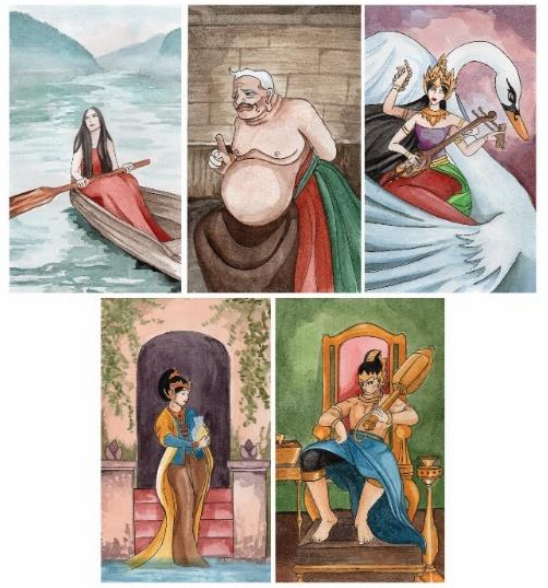

Gambar 2. Alternatif Pengorangan Wayang 2.

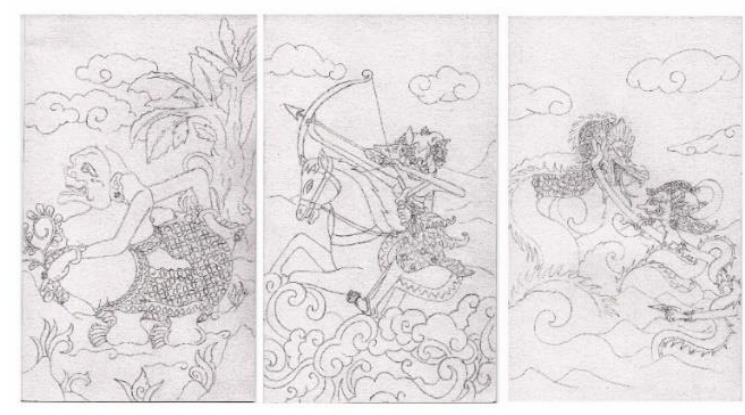

Gambar 3. Sketsa Alternatif terpilih.

Untuk bagian belakang kartu tarot, menggunakan desain Surya Majapahit yang merupakan bentuk penggambaran dari filosofi Asta Brata yang menjadi inspirasi dalam nama Astadewa Surya Majapahit berbentuk bintang delapan ujung yang melambangkan posisi dewa-dewa, dengan celah kosong di tengah yang melambangkan jiwa manusia.
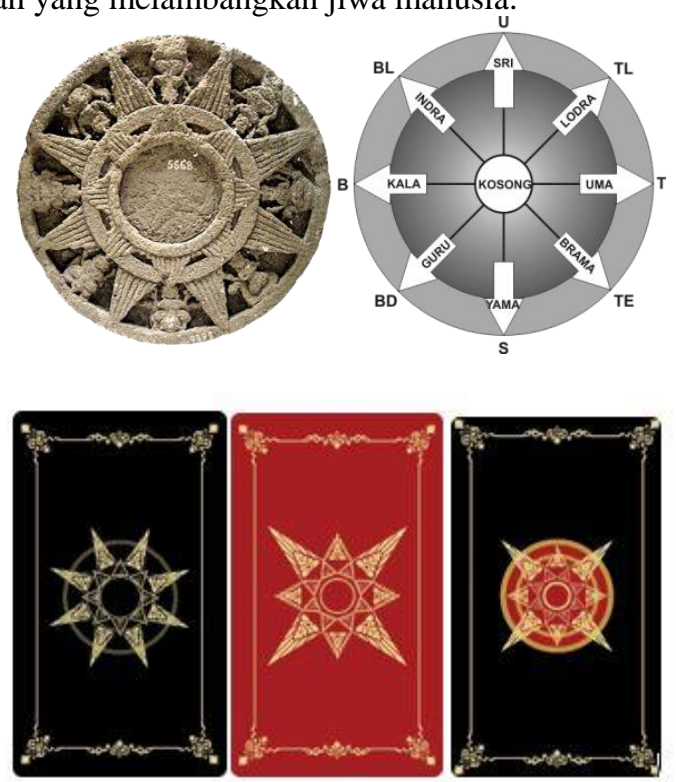

Gambar 4. Alternatif Belakang Kartu. 


\section{E. Wireframe Aplikasi Mobile}

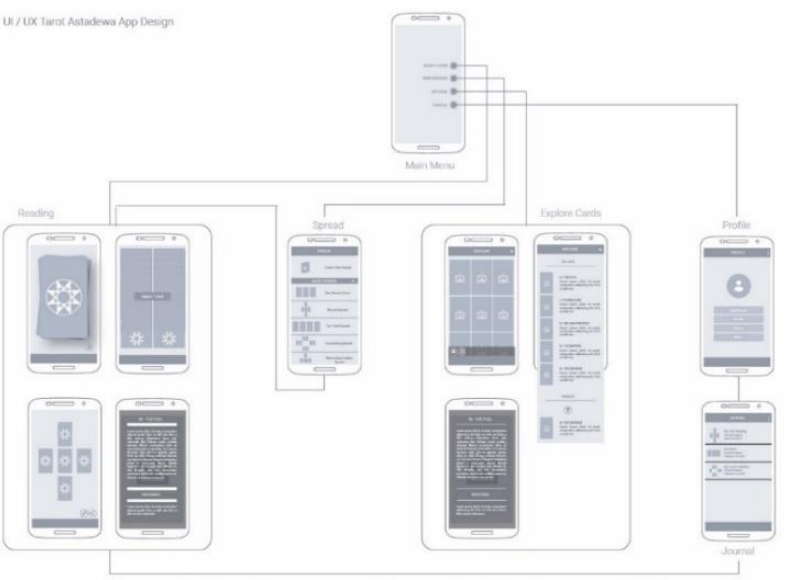

Gambar 5. Flowchart.

Model Navigasi atau Flow Chart pada Aplikasi Mobile Tarot Astadewa menggunakan model navigasi hub \& spoke, sekaligus mengadaptasi model navigasi pada aplikasi-aplikasi serupa. Adaptasi ini digunakan untuk meminimalisir kesalahan yang dibuat oleh pengguna, dengan memberikan tampilan yang mirip dengan aplikasi serupa, pengguna akan merasa bahwa dia telah menguasai aplikasi tersebut. Selain itu, Aplikasi Mobile Tarot Astadewa adalah aplikasi yang menjunjung tinggi konten, informasi, dan pembacaan tarot sekali jalan, sehingga model navigasi haruslah baik guna menyampaikan informasi tersebut secara akurat, dengan solusi, kembali kepada menu awal setiap kali selesai melakukan sebuah tugas.

\section{F. Alternatif Wireframe Aplikasi Mobile}

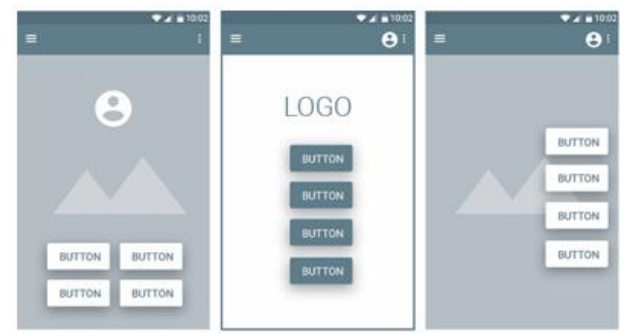

Gambar 6. Opening Screen.
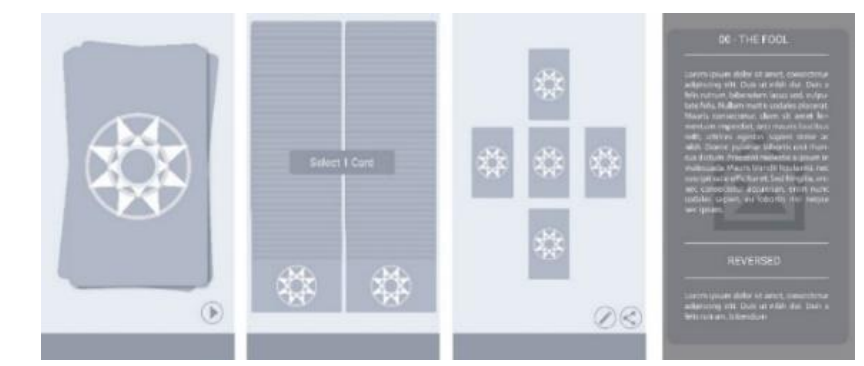

Gambar 7. Pembacaan Kartu.

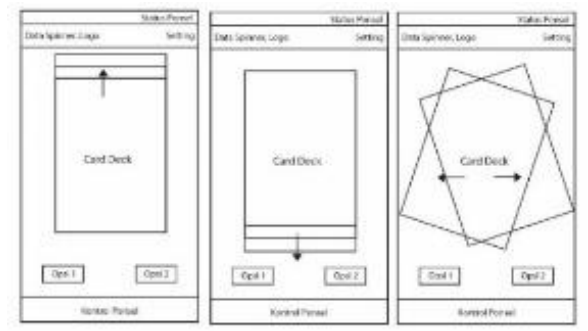

Gambar 8. Animasi Pengocokan Kartu.

\section{G. Desain Final}

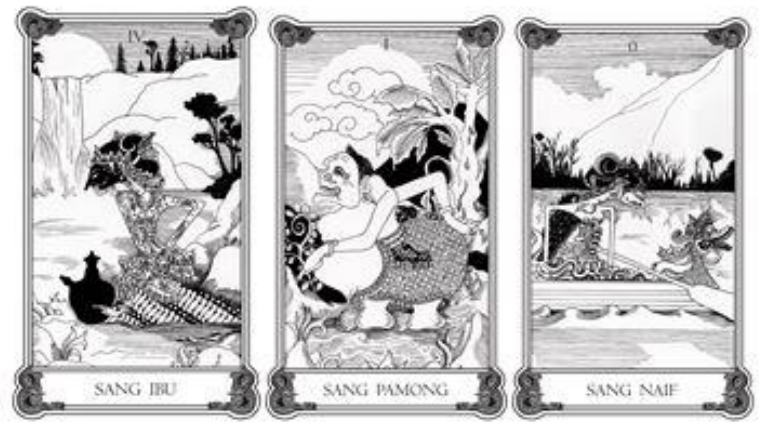

Gambar 9. Kartu Tarot Astadewa.
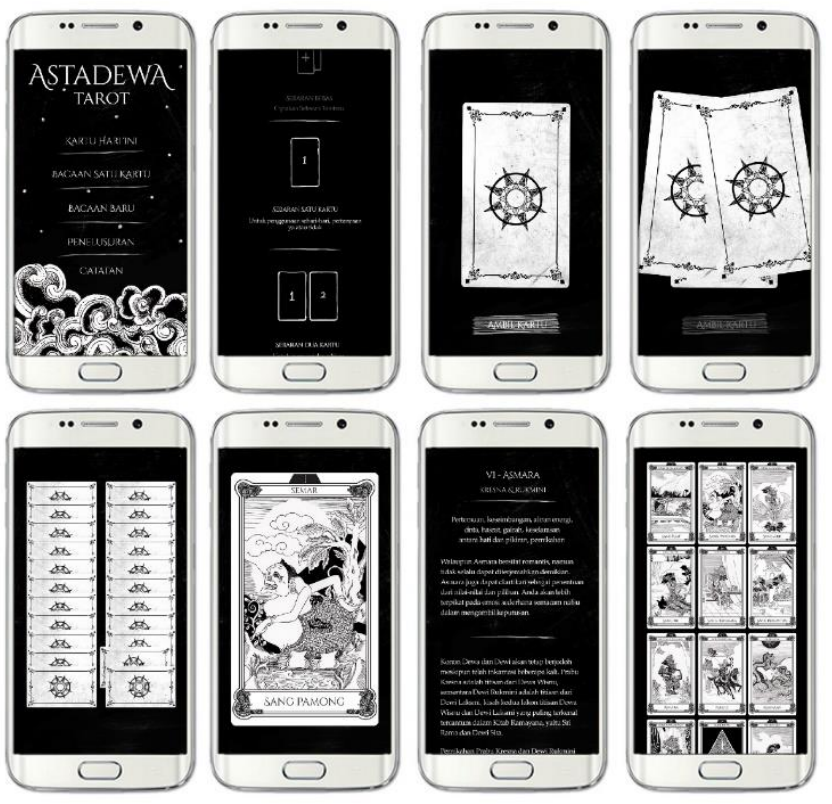

Gambar 10. Aplikasi Tarot Astadewa.

\section{KESIMPULAN}

\section{A. Kesimpulan}

Berdasarkan studi perancangan 22 kartu arkana mayor dari tarot Astadewa untuk aplikasi mobile, juga dari hasil post test dan demo, dapat ditarik beberapa kesimpulan:

1) Perancangan kartu tarot haruslah mengempasis kisah ataupun konten yang digunakan. Desain kartu tarot dapat berupa macam-macam, namun yang terpenting adalah bagaimana caranya membangun sebuah kesinambungan antara interpretasi kartu dengan konten kisah yang mampu mendukung penceritaan dalam sebuah pembacaan.

2) Dalam merancang visual kartu tarot perlu diperhatikan konten yang diambil, konten yang diambil dalam perancangan ini adalah Mahabahrata dalam wayang purwa, maka perlu diperhatikan referensi dari segi visual wayang yang sudah ada dan mengolah referensi yang sudah jadi menjadi suatu hal yang baru tanpa menurunkan segi craftmanship dari referensi.

3) Terdapat respon positif mengenai desain tarot karena tarot Astadewa terlihat berbeda dengan tarot yang sudah beredar 
di pasaran sehingga memiliki nilai jual.

4) Terdapat perbedaan pendapat pada saat demo karena desain akhir yang digunakan dinilai terlalu modern. Aplikasi mobile memiliki kesan yang modern namun penerapan konteks modern dalam perancangan aplikasi mobile tarot harus disesuaikan dengan desain tarot yang telah dibuat agar lebih memberikan pengalaman yang baik.

\section{B. Saran}

Penulis menyadari bahwa masih banyak elemen-elemen penelitian yang belum digali dengan benar-benar spesifik. Berikut merupakan hasil-hasil penelitian yang $\neg$-belum dapat disempurnakan oleh penulis juga beberapa rencana kedepan yang mungkin dapat dibuat.

1) Penggunaan gaya visual yang bersifat realistis kurang dapat menggambarkan personifikasi dari wayang itu sendiri. Wayang diciptakan dengan gaya distilisasi menjadi pipih sehingga kehilangan bentuk tiga dimensinya, estetika wayang yang kita lihat kini adalah hasil pengembangan desain selama bertahun-tahun, maka, untuk ke depannya, jika ingin membuat sebuah media adaptasi dari wayang, maka jangan tinggalkan desain wayang yang asli, agar dapat menjadi sebuah pelestarian.

2) Format aplikasi mobile memang memiliki keterbatasan untuk menampilkan animasi dan beberapa hal yang dapat membuat pengalaman membaca tarot menjadi lebih imersif, untuk pengembangan modernisasi tarot ke depannya mungkin dapat mengubah format aplikasi mobile menjadi lebih interaktif, sehingga tidak hanya sekedar digunakan untuk bacaan tetapi juga untuk permainan sehingga animasi dan pengalaman imersif dalam membaca tarot lebih didapat.

3) Dikarenakan respon positif peserta demo terhadap kartu tarot dan aplikasi mobile, maka di masa depan, diharapkan tarot dan aplikasi tarot ini akan dapat dirilis dengan desain yang lebih ditingkatkan.

\section{DAFTAR PUSTAKA}

[1] S. Millward, "Indonesia lampaui 100 juta pengguna smartphone di 2018," Techinasia, 2014. [Online]. Available: https://id.techinasia.com/jumlah-pengguna-smartphone-di-indonesia2018. [Accessed: 16-Feb-2018].

[2] V. Kong, "The 2015 U.S. Mobile App Report by ComScore," 2015. [Online]. Available: https://www.slideshare.net/VictorKongCisneros/the2015-us-mobile-app-report-by-comscore. [Accessed: 16-Feb-2018].

[3] Baidu Indonesia, "Q2 2015 Indonesia Mobile Data Report Based On MoboMarket User Data," Baidu, Inc., 2015. [Online]. Available: https://www.slideshare.net/BaiduIndonesia/q2-2015-indonesia-mobiledata-report-based-on-mobomarket-user-data-research. [Accessed: 16Feb-2018].

[4] H. Domenic, "The Fool's Dog - Tarot Apps for iOS and Android," The Fools Dog, 2017. [Online]. Available: http://www.foolsdog.com/. [Accessed: 16-Feb-2018].

[5] B. Moore, Tarot for Beginners: A Practical Guide to Reading the Cards. woodbury: Llewellyn Publications, 2010.

[6] S. Sudjarwo, H. S. Sumari, and U. Wiyono, Rupa \& Karakter Wayang Purwa. Kakilangit Kencana, 2010.

[7] W. O. Galitz, The Essential Guide to User Interface Design An Introduction to GUI Design Principles and Techniques, 3rd Edition. Indianapolis: Wiley Publishing, 2007. 